\title{
A FUNÇÃO DO ENSINO DE LITERATURA: PONTO DE CONVERGÊNCIA E DE RAMIFICAÇÃO DE PERSPECTIVAS
}

Bárbara Machado Martins ${ }^{1}$

\section{Resumo}

Apresentamos neste artigo uma discussão a respeito da função do ensino da literatura nas escolas. Dado que a extenuação dessa temática seria intangível, selecionamos um ângulo da questão no qual apresentamos um cotejo entre pressupostos teóricos resgatados de obras de especialistas em sociologia, educação e crítica literária, a saber, Marilena Chauí (2001), Antonio Candido (1995; 2002), Bordini e Aguiar (1988) e Ligia Averbuck (1985) e apreciações feitas tanto por professores de literatura como pelo dito "senso comum" (alunos e ex-alunos de literatura sem formação específica na área) em entrevistas. A eleição deste foco para discussão se justifica pela necessidade de se estabelecer um vínculo entre a fundamentação teórica estudada nas disciplinas da Licenciatura em Português e o contexto escolar. Portanto, tendo em mente tal objetivo, elencamos os pontos de aproximação e de distanciamento entre essas posições para, de alguma forma, evidenciar dados que contribuam para as pesquisas da área.

Palavras-chave: educação; ensino de literatura brasileira; função da literatura; contexto escolar.

\section{Abstract}

We present here a discussion about literature teaching function in schools. Since the exhaustion of this theme would be intangible, we selected an angle of the issue in which we present a comparison between theoretical presuppositions from sociology experts' works, education and literary criticism, such as Marilena Chauí (2001), Antonio Candido (1995; 2002 ), Bordini and Aguiar (1988) and Ligia Averbuck (1985) and appraisals made by both literature professors as the so-called "common sense" (students and formers of literature without specific graduation in the area) in interviews. The choice of this focus for discussion is justified by the need to establish a link between the theoretical foundation studied in the disciplines of the degree in Portuguese Teaching and the school environment. Therefore, keeping this goal in mind, we intend to list the points of approach and so the gaps between these positions; Thus, in some way, this research may evidence data that contribute to future researches in the area.

\footnotetext{
$1 \quad$ Graduanda em Letras pela Faculdade de Filosofia, Letras e Ciências Humanas da Universidade de São Paulo. Contato: barbara2.martins@usp.br ou barbaram.letras@gmail.com
} 
Keywords: education; Brazilian literature education; function of literature; school context.

\section{Introdução ${ }^{2}$}

Objetivamos, no presente artigo, refletir a respeito da função do ensino de literatura nas escolas. $O$ interesse por tal temática foi motivado tanto pelas discussões em classe como pelo primeiro trabalho realizado para a disciplina "Ensino de Literatura Brasileira", integrante do curso de licenciatura plena em Português e ministrada na Faculdade de Filosofia, Letras e Ciências Humanas da Universidade de São Paulo. Acreditamos que dentre as discussões do curso, a mais relevante para a temática deste artigo foi aquela motivada pelo ensaio de Marilena Chauí (2001). Nele, a autora desvela o processo de construção de um cenário característico da sociedade moderna, a saber, a marginalidade da área de ciências humanas devido à sua inessencialidade no interior da lógica capitalista. Segundo a nossa percepção, tal fenômeno está intrinsecamente ligado a problemáticas do ensino de literatura nas escolas, uma vez que a ideia deste artigo partiu de uma base empírica de situações verificadas ao longo de estágios em ambientes escolares nos quais avultou o questionamento de estudantes a respeito da função do ensino desta disciplina nas escolas e o seu proveito na vida cotidiana. Tendo que citamos até aqui o termo "função" sem a devida conceituação, cabe ressaltar antes de prosseguirmos que o compreendemos como "o papel que a obra literária [ou o estudo sistemático da literatura] desempenha na sociedade" (CANDIDO, 2002: 77).

Dissemos acima que outro elemento motivador do artigo foi um trabalho realizado para a disciplina. Temos que este consistiu em entrevistas realizadas com professores, alunos e ex-alunos no intuito de depreender experiências no ensino de literatura. Dado a riqueza dos relatos e o fato de que a extenuação da problemática supramencionada seria intangível, decidimos abordar um ângulo da questão a partir da apropriação desse método para o levantamento dos dados. Assim, disporemos de um lado referências bibliográficas nas quais estarão evidenciadas posições de especialistas em educação ou crítica literária em relação à funcionalidade do ensino de literatura e, de outro, avaliações que terão por parâmetro respostas a 
questionários on-line (cf. Fig. 1 e 2) confiados a professores, alunos e ex-alunos de literatura. Em seguida, passaremos ao confronto das avaliações a fim de compreender seus pontos de aproximação e de distanciamento. Justifica-se assim a eleição do foco do artigo: posto que realizamos um curso para a formação de professores com enfoque sobretudo teórico, buscamos, através deste trabalho, estabelecer um vínculo entre estes saberes e o contexto escolar, dada a pertinência desta questão nesse meio e a importância de termos em mente, ao entrarmos na sala de aula, a situação complexa que ela engendra.

\section{Fundamentação teórica}

Conforme mencionado na seção anterior, o interesse pela temática do papel do ensino da literatura surgiu a partir de uma discussão em classe a respeito das considerações de Marilena Chauí (2001) sobre a incapacidade de posicionamento da área de humanidades frente à sociedade capitalista contemporânea. Segundo a autora, a lógica capitalista penetrou na Universidade que, submetendo-se à economia, contribuiu para a criação de um "mercado intelectual" no qual conhecimento passou a ser valorizado como uma força econômica produtiva. Obviamente essa "universidade de serviços e resultados" (idem: 168) rejeita as humanidades, tendo em vista a inaplicabilidade de suas pesquisas segundo essa lógica. O que notamos é que tal situação se estende ao imaginário da sociedade como um todo, interferindo desse modo nas práticas de ensino de literatura, como atesta Ligia Averbuck ao afirmar que é no "aspecto de gratuidade da poesia [e da literatura] que estará a base de sua exclusão das áreas ditas 'sérias' dos conhecimentos, o que, certamente, é inspirado numa visão utilitarista e pragmática da educação e da vida em geral."(1985: 65).

Sabemos, no entanto, que muito embora a literatura sofra com a indiferença de boa parcela da sociedade, seu estudo sistemático é bastante difundido, sendo a questão da sua funcionalidade ponto de interesse comum a numerosos estudos de especialistas em educação e crítica literária. Condizente ao que propusemos na introdução deste artigo, pretendemos esboçar algumas dessas apreciações no intuito de confrontá-las por um lado com a posição de professores e, por outro, com 
a percepção do "senso comum", ou seja, a contraparte social representada por alunos e ex-alunos de literatura. Deste modo, optamos por iniciar a discussão a partir de um paralelo entre as posições de Antonio Candido (1995; 2002), Ligia Averbuck (1985) e Bordini e Aguiar (1988). A revisão dos estudos de Candido se justifica pela aproximação entre as funções da literatura elencadas em seu ensaio e aquelas inventariadas no manual escolar ${ }^{3}$ utilizado por parte dos ex-alunos que colaboraram com a pesquisa. O recurso ao texto de Averbuck refere às considerações expostas pela autora a respeito do ensino de poesia, algumas das quais, acreditamos, podem abarcar problemáticas do ensino da literatura de modo geral. Finalmente, o apelo às considerações de Bordini e Aguiar se explica pela qualidade e riqueza da pesquisa realizada pelas autoras sobre práticas de ensino de literatura.

A primeira das funções expostas por Candido remete ao papel humanizador da literatura através da síntese e da projeção da experiência humana através dos textos (2002: 80). Tal concepção é reforçada por Averbuck, que adverte para a "importância de um ensino voltado para a criatividade como meio formador da sensibilidade" (1985: 67). A partir desta função, Candido elenca outras a ela subordinadas, como é o caso da função psicológica traduzida na necessidade humana universal de produção e fruição de ficção e de fantasia (2002: 80) o que, nas palavras de Averbuck, consiste no caráter libertador da poesia (e da literatura) através da possibilidade de expansão do real (1985: 67). Esse processo, ao apelar para o devaneio, fornece condições para "atividades espirituais legítimas" (CANDIDO, 2002: 82), como a criação e a reflexão a partir da realidade concreta da qual partiu o texto literário, derivando daí a terceira função elencada por Candido: a função integradora e transformadora da criação literária em relação à realidade (idem: ibidem) e ao próprio sujeito. Ligam-se a esta colocação as posições de Bordini e Aguiar (1988) e Averbuck (1985). As duas primeiras autoras defendem que a educação literária deve, necessariamente, fundamentar-se na noção de transformação sociocultural de modo que a finalidade desse processo seja a conquista, por parte do aluno, de "uma postura crítica ante o mundo e a práxis social" (1988: 43). Nessa perspectiva, Averbuck prevê o papel imprescindível da arte

3 CEREJA, W. R.; MAGALHÃES, T. C. Literatura Brasileira: em diálogo com outras literaturas e outras linguagens. São Paulo: Atual, 2005. p.25-26. 
no desenvolvimento da personalidade humana, dado o seu papel social "modificador, subversivo, em relação à mediania, à tradição, ao continuísmo das normas" (1985: 66).

Tendo em conta as propriedades acima expostas, Candido estabelece ainda duas funções da literatura as quais, segundo nosso julgamento, são aquelas que mais se justificam em contextos escolares. A primeira delas é a função educativa que, relacionada à função formativa da personalidade, consiste na preparação do indivíduo para a vida social, contudo, de acordo com o autor, tal função é extremamente complexa na medida em que se contrapõe aos ideais pedagógicos, uma vez que não consiste em uma atividade delimitada e dirigida nem tampouco em um manual de virtude e boa conduta, pelo contrário, nela - como na vida - estão amalgamados os valores positivos e negativos da sociedade, de modo que a formação através das obras reflete a educação impactante da vida (2002: 83). A última das funções indicada pelo autor é aquela que, de um modo geral, engloba as demais, posto que se trata da "função de representação de uma realidade social e humana". Assim, o crítico esclarece que, embora a obra literária possua autonomia de significado ela é, ao mesmo tempo, estritamente ligada ao real que a originou e o qual está sujeito à sua capacidade transformadora, situação que faculta maior inteligibilidade do leitor quanto a esta mesma realidade (idem: 86). Podemos notar que tal conceito está vinculado àquilo exposto acima a respeito da noção de transformação sociocultural discutida através das considerações de Averbuck e Bordini e Aguiar. Por fim, dada a relevância desta temática, Candido expande a discussão a outro ensaio (1995) no qual, avaliando a influência que a literatura pode exercer na formação da personalidade humana, o autor prescreve que o acesso a esta - como a outros objetos da cultura - deve ser um direito humano inalienável (idem: 191) o que, conforme discutiremos, pode consistir em um elemento relacionado à disciplinarização desta área nas escolas. 


\section{Articulação com os dados dos questionários dos professores}

Pretendemos iniciar a discussão a partir da apresentação das perguntas orientadas aos professores para, em seguida, confrontarmos as suas respostas à revisão bibliográfica da seção anterior e, por fim, compararmo-las àquelas destacadas pelo senso comum na próxima seção. Organizamos as tabelas (cf. Tab. 1 e 2) segundo os códigos $\mathbf{P}$ para os professores, $\mathbf{A}$ para alunos e ex-alunos $\mathbf{e}$ numeração de $\mathbf{1}$ a $\mathbf{5}$ para as questões de modo a simplificar as referências (p.ex. P14: professor 1, resposta 4).

1. Há quanto tempo você ministra aulas de literatura?

2. Como você leciona essa disciplina?

3. Para você, qual é a função do ensino de literatura nas escolas?

4. Você já passou por situações de questionamento por parte dos estudantes a respeito da finalidade do ensino dessa disciplina? Se sim, você imagina os motivos que impulsionaram os alunos a tal questionamento?

Buscamos, com as duas primeiras questões, depreender alguns dados a respeito do perfil dos professores entrevistados, visto que a este podem estar relacionadas as posições evidenciadas nas questões 3 e 4 , uma vez que a percepção docente a respeito da funcionalidade da literatura pode operar na seleção metodológica e, consequentemente, tanto o seu perfil como a sua metodologia podem estar ligados à receptividade dos alunos e ao posicionamento destes perante a literatura (questão 4). Portanto, a análise da terceira questão consiste no cerne deste tópico, a qual é complementada pela última questão, motivada pelo interesse em saber se a situação exposta na introdução deste artigo está presente na prática desses docentes e, em caso positivo, averiguar a visão do professor a respeito desse fenômeno.

Como podemos notar pelas respostas (cf. Tab. 1), os três professores entrevistados contam com uma carreira recente (entre seis meses e dois anos) e atuam em escolas regulares e cursinhos preparatórios para o Vestibular ou Ensino Médio profissionalizante. Percebemos que esses docentes demonstram certo 
desconforto em relação às imposições das suas instituições de ensino (avaliação tradicional, ensino apostilado e determinação das obras para a leitura) e tentam, na medida do possível, intervir no processo educativo de modo a atenuar tais exigências com debates e reflexões sobre as leituras.

Em relação ao papel do ensino da literatura, as respostas versaram desde a humanização, o desenvolvimento das habilidades reflexiva, leitora e escrita (P1-3), passando pelo conhecimento histórico-cultural, elemento identitário, novamente desenvolvimento da capacidade leitora e exercício interpretativo (P2-3) até a ampliação do repertório artístico-cultural, o direito à fruição estética, reflexão sobre a linguagem, sobre a vida interior e sobre a sociedade (P3-3). Assim, constatamos que algumas destas perspectivas vão de encontro àquilo proposto pelos pensadores na seção anterior, como é o caso da sensibilização/humanização por meio desta arte (AVERBUCK, 1985: 67; CANDIDO, 2002: 80), reflexão sobre o eu, a realidade e o contexto social (CANDIDO, 2002: 82; BORDINI \& AGUIAR, 1988: 43), 0 conhecimento histórico-cultural, associado à função representativa de realidades sociais (CANDIDO, 2002: 85-86) e à função psicológica caracterizada pela necessidade e direito à fruição estética (CANDIDO, 2002: 80). Por outro lado, notamos que os professores elencam uma nova função em relação àquelas focalizadas nos autores supracitados, esta, de cunho sobretudo utilitário, concentrase no desenvolvimento de habilidades linguísticas como a leitura, escrita e interpretação.

Por fim, notamos que os três professores já vivenciaram situações de indagação por parte dos alunos a respeito da funcionalidade do ensino de literatura e do trabalho com o cânone. De acordo com suas impressões, tal aversão é originária de uma concepção "prática" da vida segundo a qual não há espaço para atividades artístico-reflexivas como o estudo literário (P1-4) e da imposição tanto de obras como do próprio ato leitor (P2-4, P3-4). Notamos assim uma aproximação entre a temática explanada por Chauí e a ponderação da primeira professora na medida em que ela confirma aquilo que anunciamos na introdução deste artigo, ou seja, o fato de a questão da inessencialidade das humanidades, iniciada na Universidade, ter se expandido ao imaginário social e impregnado o ambiente escolar, interferindo assim em práticas pedagógicas. Os dois outros professores, por 
sua vez, consideram que a contestação dos alunos é impelida pela imposição das leituras. Percebemos, assim, uma crítica ao cânone subjacente aos questionamentos dos alunos, uma vez que muitos deles apresentam hábitos leitores - conforme afirma a segunda professora (P2-4) - dos quais os clássicos estão excluídos. Cabe, portanto, um breve comentário a respeito dessa questão no intuito de discutir as circunstâncias que incitam os alunos à renúncia. Propomos iniciar a argumentação a partir das explanações de Roberto Reis. Segundo o autor:

o conceito de cânon implica um princípio de seleção (e exclusão) e, assim, não pode se desvincular da questão do poder: obviamente, os que selecionam (e excluem) estão investidos da autoridade para fazê-lo e o farão de acordo com seus interesses (...). Convém atentar ainda para o fato de que o exercício desta autoridade se faz num determinado espaço institucional (1992: 70).

Desse modo, entendemos que a seleção e a imposição das obras que farão parte do currículo têm subjacentes questões de ordem político-ideológica cujos valores muitas vezes contrastam com aqueles dos alunos e também dos professores, como o atesta a segunda professora (P2-4). Tal constatação pode ser reforçada pelo argumento levantado por Bordini e Aguiar a respeito da sujeição dos currículos à ideologia dominante. Segundo as autoras, as propostas educacionais repetem o modelo da estrutura social na qual estão inseridas, o que acaba por restringir a função da escola ao "reforço ideológico de um Estado autoritário" (1988: 35). Os organismos responsáveis pela organização dos currículos, por sua vez, negam tal cenário, buscando sustentar o recurso a essa "aristocracia de textos" (REIS, 1992: 71) sob o argumento de que tais obras possuem qualidades intrínsecas. Sabemos, entretanto, que esta premissa é falsa, uma vez que o revestimento de valores às obras é realizado numa dada conjuntura histórica e que, a cada nova geração de leitores, estes estão sujeitos a revisões, tendo que aqueles anteriormente preconizados podem já não encontrar amparo em momentos posteriores e, inclusive em uma mesma geração, os valores atribuídos por grupos sociais distintos podem não ser os mesmos. Deriva pois dessa situação um relevante fator de aversão do aluno à literatura, uma vez que constatamos o distanciamento ideológico entre os valores deste e aqueles preconizados pelo Estado e confirmados nas obras selecionadas do cânone. 


\section{Articulação com os dados dos questionários dos alunos}

Tendo em mente as considerações esboçadas até este ponto, introduziremos a análise dos dados dos questionários dos alunos e ex-alunos (cf. Tab. 2), seguindo o mesmo método da seção anterior. Destarte, apresentamos as perguntas:

1. Atualmente, você é estudante do Ensino Médio? Se sim, em qual série você está matriculado? Se não, há quantos anos terminou os seus estudos no Ensino Básico e qual a sua atual área de formação?

2. Você tem (ou já teve) aulas de literatura? Como são (ou eram) essas aulas?

3. Você gosta (ou gostava) dessas aulas? Por quê?

4. Você acha que aprende ou já aprendeu algo útil para a sua formação ou para a sua vida nessas aulas? Se sim, o que? Se não, por quê?

5. Você percebe alguma função no ensino de literatura nas escolas? Se sim, qual função? Se não, por quê?

Procuramos, com as duas primeiras questões, apurar se o perfil dos entrevistados convinha à pesquisa, visto que delimitamos o corpus entre alunos ou ex-alunos que tenham tido alguma experiência recente no ensino de literatura. No caso do perfil dos ex-alunos (atualmente distribuídos entre as áreas de ciências humanas, exatas e biológicas) estabelecemos que o distanciamento destes em relação ao Ensino Básico deveria ser de seis anos no máximo. Assim, contamos com um corpus de treze questionários, dos quais cinco foram respondidos por alunos da "Escola Estadual Professor Andrônico de Mello" e oito foram encaminhados a ex-alunos de diversas áreas de formação. Ainda em relação à segunda pergunta, temos que esta se relaciona à terceira na medida em que ambas buscam evocar as reminiscências dos entrevistados, posto que acreditamos que tais lembranças fornecem vestígios à compreensão das respostas das duas últimas questões. Estas, por sua vez, também estão ligadas na medida em que supomos que a maneira pela qual o sujeito considera o seu aproveitamento nessas aulas (questão 4) influi no modo segundo o qual ele configura a função social do ensino de literatura contemplada na última pergunta. 
Assim, temos como respostas às questões 2 e 3 descrições de metodologias e perfis de professores. No que refere às metodologias, depreendemos que a maioria destes jovens teve um ensino restrito ao estudo do cânone o que, conforme veremos, parece influir nas suas concepções a respeito da literatura e da sua funcionalidade. Em relação aos perfis de professores, notamos um fato curioso: muitos dos entrevistados (A1-3, A4-3, A6-3, A9-2, A11-3, A13-3) associam diretamente a disciplina ao professor, de modo que justificam o seu gosto ou desgosto pelas aulas em relação à sua afinidade ao docente e/ou metodologia e não pelo conteúdo propriamente dito. Podemos compreender tal posição ao apelar para as considerações de Averbuck. A autora afirma que o "entusiasmo do professor" (1985:69) no trabalho com o texto literário é um dos elementos essenciais do processo de aproximação do aluno já que, na sua concepção, "a descarga emocional provocada pela sensibilização a um texto poético tem seu circuito interrompido antes de chegar ao aluno, se ele passar por um professor indiferente e fechado ao apelo da arte." (idem: ibidem). Portanto, além dos casos esboçados acima, explicam-se igualmente tanto a posição do aluno que afirmou gostar das aulas pela reflexão incitada (A5-3) como aquela dos estudantes que admitiram a sua aversão às aulas devido à falta de aprofundamento no estudo dos textos (A1-3, A102). Finalmente, encontramos casos de alunos que afirmaram gostar das aulas exclusivamente pelo ato da leitura (A2-3, A10-3) e pelo conhecimento históricocultural adquirido (A7-3, A12-3).

Encontramos, nas questões 4 e 5, as respostas mais variadas. Constatamos que a maior parte do senso comum (A1-4, A4-4, A5-5, A9-4, A12-5, A13-5) partilha da posição de dois dos professores entrevistados (P2-3, P3-3) a respeito da função social do ensino da literatura (ou mesmo considera esta a sua principal aquisição nas aulas) em virtude do conhecimento histórico-cultural veiculado. Ainda nessa linha, dois dos entrevistados concordam com os professores (P2-3, P3-3) a respeito da importância da literatura na constituição da identidade nacional (A4-5, A5-5). Assim, depreendemos nessas apreciações um paralelo com aquilo que Candido denomina a "função de representação de uma realidade social e humana" (2002: 8586) segundo a qual a obra, a partir de uma independência dependente da realidade, é inspirada e tem autonomia em relação à mesma, possibilitando assim a reflexão e assegurando maior inteligibilidade do leitor quanto a essa realidade. 
Segundo essa perspectiva, o quinto entrevistado atenta para a importância da literatura na manutenção da tradição (A5-5) e, como o primeiro entrevistado (A1-5) e os três professores, reconhece o papel da disciplina no desenvolvimento do espírito crítico - "atividades espirituais legítimas", segundo Candido (2002: 82) -, apreendendo assim o potencial dessa arte na transformação sociocultural (BORDINI \& AGUIAR, 1988: 43) através de sua capacidade de subversão, desalienação e libertação dos indivíduos (AVERBUCK, 1985: 67). Percebemos assim a referência àquilo que Candido denomina "função educativa" da literatura, a qual se traduz pela preparação do indivíduo para a vida social, uma vez que, conforme afirmaram esses entrevistados, o estudo literário foi um importante instrumento na calibração dos seus olhares e percepções quanto ao mundo (A1-5, A5-4). Segundo essa lógica, podemos considerar ainda a resposta de uma aluna à pergunta do porquê ela gostava das aulas, a qual tivemos como resposta a asserção de que ela "coloca em outros contextos o que aprende em literatura" (A13-4), ou seja, notamos uma situação de ensino que faz sentido para a estudante, uma vez que ela deduz que o conteúdo trabalhado não se esgota na sala de aula, muito pelo contrário, serve para aprimorar a sua capacidade perceptiva perante a realidade que a cerca.

Outros entrevistados, por sua vez, seguiram por uma orientação inversa ao adotar uma perspectiva pragmática na concepção dos objetivos para o ensino da literatura. Salientamos que as funções elencadas apresentam-se como inovadoras em relação às posturas dos críticos esboçadas no tópico "fundamentação teórica", contudo condizentes com parte das respostas dos professores à terceira questão. Trata-se do desenvolvimento de habilidades linguísticas, como a aquisição vocabular, aprimoramento da escrita e amplificação das capacidades leitora e interpretativa (A1-4, A7-4, A8-4). Sabemos que tais características consistem em frutos do estudo do texto literário, entretanto essa perspectiva precisa ser dosada como fizeram os professores e alguns desses alunos -, pois tais aquisições não podem ser consideradas como principais objetivos do ensino de literatura, uma vez que o trabalho com gêneros textuais não literários poderia gerar efeitos similares. Ainda nessa ótica, depreendemos casos extremos nos quais os jovens consideram aquisições práticas de suas experiências com o ensino literário e estabelecem funções utilitárias para a disciplinarização desta área nas escolas. Este é o caso dos sujeitos que julgam que este ensino tem por finalidade a preparação para o 
Vestibular (A2-5, A7-2, A12-4), ou apenas o estímulo à leitura (A2-5, A7-5, A9-5) para o qual, convenhamos, não seria necessário o trabalho exclusivo com o texto literário pois, conforme discutimos a respeito do aprimoramento das habilidades linguísticas, o incentivo à leitura não é algo que possa ser alcançado exclusivamente pelo trabalho com esses gêneros.

Por fim, três entrevistados afirmam que as suas experiências de ensino de literatura não foram de forma alguma profícuas (A6-4, A10-4, A11-4) e três não reconhecem qualquer função do ensino desta disciplina nas escolas (A3-5, A6-5, A11-5). Destacamos ainda duas respostas ambíguas que, acreditamos, podem ter sido ocasionadas pela pressão e decorrente receio dos entrevistados em demonstrar uma imagem de ignorância ou ingenuidade ao responder a um questionário desta sorte. No primeiro caso o entrevistado afirma que as aulas "não pareciam de muita serventia" (A10-3), o que justificaria a sua afirmação de não ter assimilado nada positivo nessas experiências (A10-4); entretanto, contrariamente às respostas anteriores, na última questão ele elenca três funções para o ensino desta disciplina (A10-5): a erudição da população, o desenvolvimento da habilidade leitora e, consequentemente, da capacidade reflexiva - noções que remetem à discussão acima a respeito do papel transformador da literatura, todavia, não podemos avaliar precisamente tal posicionamento devido à ambivalência das respostas evidenciadas. No segundo caso o entrevistado alega não gostar das aulas porque "se ensinam muitas coisas desnecessárias" (A3-3), mas garante ter aprendido algo relevante para a sua formação na questão 4, entretanto a responde genericamente com a evasiva de que "alguma coisa sempre é importante" (A3-4), de modo que a sua posição fica evidente apenas na resposta à última questão (A3-5), quando o aluno caracteriza a área como inútil.

Podemos supor - através da análise dos casos analisados em que os entrevistados estabelecem funções puramente utilitárias para o ensino da literatura ou renegam o seu papel nos ambientes escolares - a confirmação da intuição da primeira professora (P1-4) ao precisar que situação de aversão dos alunos ao estudo literário se deve a uma ideologia social na qual se coloca o utilitarismo e as forças econômicas à frente de qualquer atividade sensibilizadora de cunho artísticoreflexivo. Conforme discutimos ao fazer um paralelo entre as posições de Marilena 
Chauí e Ligia Averbuck, esses questionamentos remetem à problemática da marginalização da área de ciências humanas - e dentre elas a literatura - segundo a ótica capitalista e, em consequência, o seu eco no ambiente escolar.

Compreendidos os pontos de aproximação entre as perspectivas cabe, por fim, um comentário relativo às funções ou problemáticas elencadas pelos especialistas e professores não contempladas pelo senso comum. O primeiro dos casos a se salientar é o fato de esses alunos e ex-alunos não terem citado a imposição da leitura do cânone como fator de repulsa, o que nos obriga a deixar em suspenso 0 argumento mais recorrente entre os professores (P2-4, P3-4) na tentativa de interpretar a aversão discente. O único dado dessa situação que podemos pormenorizar é o fato de a maior parte dos entrevistados contar com um histórico de ensino pautado pelo cânone o que, segundo nossa percepção, parece ter influído nas suas concepções a respeito da literatura, tendo que muitos deles a veem exclusivamente como conjunto de textos-modelo (A2-2, A7-4, A9-5). Tal noção, conforme explicam Bordini e Aguiar, "implica a imposição de normas linguísticas, estéticas e ideológicas" (1988: 38), de modo que essas pessoas circunscrevem a instrução literária apenas em função do apuro das habilidades linguísticas, ignorando assim todas as potencialidades que 0 trabalho com a literatura pode gerar, conforme vimos discutindo.

Outros pontos não mencionados pelo senso comum - porém coincidentes entre os estudos dos especialistas e as perspectivas docentes - foram o papel humanizador da literatura através da sensibilização do leitor, a função psicológica condensada na fruição do texto literário e direito de acesso a este bem cultural. Tal fato nos surpreendeu pois, conforme anunciamos no tópico "fundamentação teórica", recorremos às considerações de Antonio Candido pelo fato de termos depreendido que o manual didático utilizado pela maior parte dos ex-alunos de literatura - os quais partilharam do mesmo ambiente escolar da autora deste artigo - faz referência às funções delineadas por Candido, as quais, conforme lembramos, foram ainda enfatizadas pela professora em discussões. Portanto, o alheamento a essas funcionalidades em prol daquelas mais utilitárias parece indicar, conforme discutimos acima, uma concepção pragmática da educação e da vida segundo a perspectiva da maior parte dos entrevistados. 


\section{Considerações Finais}

Terminadas as análises dos dados dos questionários, podemos tecer algumas considerações a respeito das tendências gerais observadas quanto ao posicionamento de especialistas em sociologia, educação e crítica literária, professores, alunos e ex-alunos no tocante à funcionalidade do ensino de literatura nas escolas do Ensino Básico. Conforme esclarecemos na introdução deste artigo, o interesse pela temática foi impulsionado pelos estudos de Marilena Chauí (2001) a respeito do sentimento de inessencialidade remetido às ciências humanas nas sociedades modernas, as quais, configuradas segundo os preceitos da lógica capitalista, colocam o utilitarismo e as forças econômicas acima de quaisquer atividades de cunho artístico-reflexivo, como a literatura. Assim, dado que essa ideologia contagiou a sociedade de forma ampla, supomos a sua interferência nas práticas de ensino de literatura nas escolas e buscamos comprovar tal hipótese a partir da aproximação a sujeitos que estão ou estiveram recentemente envolvidos com práticas de ensino de literatura.

Destarte, consoante ao o que expusemos nas seções precedentes, confirmamos tal conjectura a partir do cotejo entre a intuição de uma das professoras a respeito da aversão dos alunos à disciplina e aquelas de alunos que caracterizaram a área como inútil, não reconhecendo assim qualquer função para o ensino de literatura. Entretanto, ainda segundo essa perspectiva pragmática, constatamos uma tendência inédita segundo a qual os alunos estabeleceram funções puramente utilitárias para 0 ensino desta disciplina, como 0 desenvolvimento de habilidades linguísticas, incentivo à leitura e até mesmo preparação para o Vestibular. Destacamos que embora algumas dessas aptidões possam ser aprimoradas pelo estudo literário, devemos partilhar da ponderação dos docentes, que as consideraram associadas a outras funções, como é o caso da humanização/sensibilização do indivíduo (AVERBUCK, 1985: 67; CANDIDO, 2002: 80), o seu papel no desenvolvimento da capacidade reflexiva e a sua potencialidade de transformação sociocultural (CANDIDO, 2002: 82; BORDINI \& AGUIAR, 1988: 43), a função representativa da realidade relacionada ao conhecimento históricocultural (CANDIDO, 2002: 85-86) e, por fim, a função psicológica caracterizada pela necessidade e direito à fruição estética (CANDIDO, 2002: 80). 
Notamos que a posição majoritariamente assumida pelos alunos em relação a estas últimas funções foi a ampliação do repertório artístico, histórico e cultural e, em números mais tímidos, o desenvolvimento da capacidade reflexiva dos sujeitos sobre si mesmos e sobre a realidade que os cerca, configurando aquilo que Candido denomina de forma geral a "função educativa" da literatura (2002: 83), efetivada na preparação do indivíduo para a vida em sociedade. Assim, inferimos que não é possível depreender uma função para o ensino de literatura, dado a natureza plural e a potencialidade desta área. A posição mais esclarecida é admitir os diversos papéis que o contado com as obras literárias pode ter na formação desses jovens. Isto posto, acreditamos que alcançamos os objetivos projetados na introdução deste artigo, uma vez que pretendíamos, através da aproximação às perspectivas de sujeitos concretos do processo de ensino, esclarecer alguns pontos dessa argumentação a partir do confronto entre os conceitos veiculados na academia com as compreensões desses sujeitos a fim de, na medida do possível, nos prepararmos para o embate com essa situação complexa no momento em que entrarmos em sala de aula.

\section{Referências Bibliográficas}

AVERBUCK, Ligia Morrone. A poesia e a escola. In: ZILBERMAN, Regina (org.). Leitura em crise na escola. Porto Alegre: Mercado Aberto, 1985.

BORDINI, Maria da Glória; AGUIAR, Vera Teixeira. Necessidade de metodologia. In: Literatura. A formação do leitor. Porto Alegre: Mercado Aberto, 1988.

CANDIDO, Antonio. A literatura e a formação do homem. In: Textos de intervenção. São Paulo: Duas cidades/Editora 34, 2002.

O direito à literatura. In: Vários escritos. São Paulo: Duas Cidades,1995.

CHAUÍ, Marilena. O mal estar na universidade. In: Escritos sobre a universidade. São Paulo: Ed. UNESP, 2001.

REIS, Roberto. Cânon. In: JOBIM, José Luís (org.). Palavras da crítica. Rio de Janeiro: Imago, 1992. 


\section{Anexo 1}

Figura 1 - Reprodução do questionário on-line para os docentes

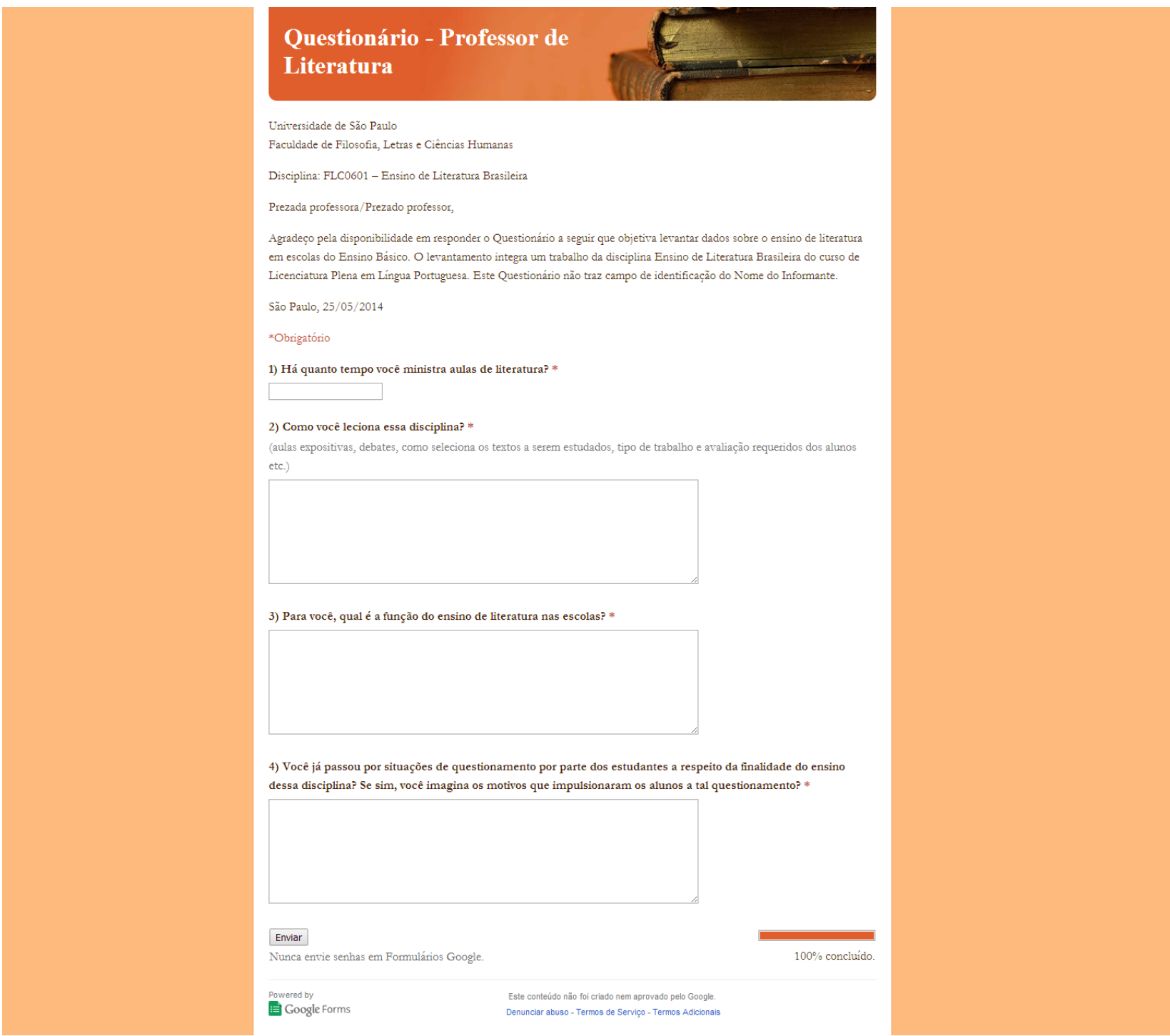

\section{Anexo 2}

Figura 2 - Reprodução do questionário on-line para os alunos e ex-alunos 


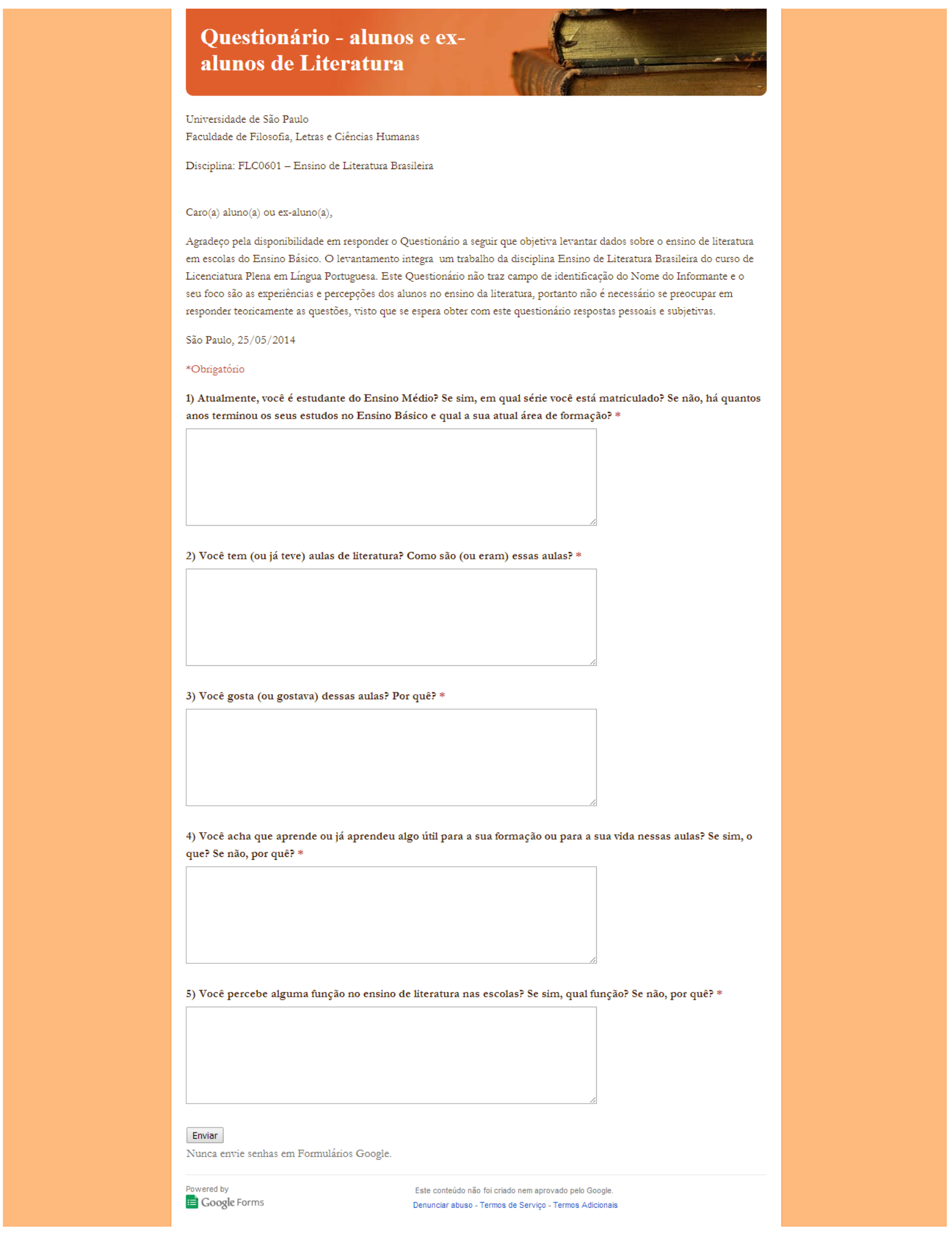




\section{Anexo 3}

Tabela 1 - Respostas dos docentes ao questionário

\begin{tabular}{|c|c|c|c|c|c|}
\hline & $\begin{array}{l}\text { Data e } \\
\text { hora }\end{array}$ & $\begin{array}{l}\text { 1) Há quanto } \\
\text { tempo você } \\
\text { ministra } \\
\text { aulas de } \\
\text { literatura? }\end{array}$ & 2) Como você leciona essa disciplina? & $\begin{array}{l}\text { 3) Para você, qual é a função do } \\
\text { ensino de literatura nas escolas? }\end{array}$ & $\begin{array}{l}\text { 4) Você já passou por situações de } \\
\text { questionamento por parte dos } \\
\text { estudantes a respeito da finalidade } \\
\text { do ensino dessa disciplina? Se sim, } \\
\text { você imagina os motivos que } \\
\text { impulsionaram os alunos a tal } \\
\text { questionamento? }\end{array}$ \\
\hline P1 & $\begin{array}{c}25 / 05 / 2014 \\
16: 38: 43\end{array}$ & $\begin{array}{l}1 \text { ano e } 5 \\
\text { meses }\end{array}$ & $\begin{array}{l}\text { Aulas expositivas, debates prévios sobre } \\
\text { os temas, leitura e reflexão de textos } \\
\quad \text { literários. } \\
\text { Avaliação: participação do aluno e } \\
\text { avaliação tradicional exigida pela escola. }\end{array}$ & $\begin{array}{l}\text { Desenvolver o senso de humanidade } \\
\text { nos alunos, o lado crítico e reflexivo. } \\
\text { Além de aprimorar as habilidades de } \\
\text { leitura e escrita. }\end{array}$ & $\begin{array}{l}\text { Sim, acredito que este questionamento } \\
\text { tem por base a ideia de que o estudo só } \\
\text { é necessário para alcançar determinada } \\
\text { nota ou determinada função "prática". } \\
\text { Refletir não é necessário, criticar, } \\
\text { questionar, buscar aquilo que está além } \\
\text { do óbvio. É desafiador, portanto, não } \\
\text { apenas ensinar Literatura, mas abrir a } \\
\text { mente do aluno de modo que ela esteja } \\
\text { apta a receber novos conhecimentos, } \\
\text { assim como questioná-los. }\end{array}$ \\
\hline P2 & $\begin{array}{l}\text { 25/05/2014 } \\
19: 08: 28\end{array}$ & 02 anos & $\begin{array}{l}\text { Trabalhamos com material apostilado e, } \\
\text { por isso, as aulas são expositivas e } \\
\text { também inserimos vídeos com material } \\
\text { pertinente ao conteúdo. Estamos } \\
\text { divididos por módulos em que temos } \\
\text { explicação das escolas/movimentos } \\
\text { literários e na aula seguinte análise de } \\
\text { texto para reconhecer as características } \\
\text { mencionadas na aula anterior. } \\
\text { programa segue uma suposta ordem } \\
\text { cronológica das escolas ou movimentos: } \\
\text { começa-se por Trovadorismo e segue-se } \\
\text { até a terceira fase modernista, finalizando }\end{array}$ & $\begin{array}{l}\text { A escola tem múltiplas formas de } \\
\text { transmitir a cultura de uma sociedade e } \\
\text { de um período. A literatura é uma das } \\
\text { formas de conhecer e reconhecer um } \\
\text { povo, uma história e uma sociedade. } \\
\text { Ainda que sejam prestigiados pelos } \\
\text { pais, o material apostilado tem muitos } \\
\text { pontos negativos. A organização } \\
\text { modular acaba por limitar o trabalho } \\
\text { que poderia ser interdisciplinar. É } \\
\text { importante que os próprios professores } \\
\text { reconheçam-se como figuras } \\
\text { fundamentais na valorização do ensino }\end{array}$ & $\begin{array}{l}\text { Há sempre alunos que questionam por } \\
\text { que estão estudando literatura e, } \\
\text { sobretudo, por que têm que ler os } \\
\text { clássicos (infelizmente, nós - a escola - } \\
\text { impomos). Creio que os alunos fazem } \\
\text { essas perguntas por não verem sentido } \\
\text { na imposição que é feita como disciplina } \\
\text { escolar. Um aluno que tem acesso a } \\
\text { livros porque quis ou os descobriu numa } \\
\text { cultura familiar de leitura, dificilmente faz } \\
\text { essa pergunta porque entende que a } \\
\text { leitura desenvolve a imaginação, ensina, } \\
\text { diverte e, sobretudo, transforma a }\end{array}$ \\
\hline
\end{tabular}

Revista Eletrônica Literatura e Autoritarismo: Dossiê no 15 - ISSN 1679-849X 


\begin{tabular}{|c|c|c|c|c|c|}
\hline & & & $\begin{array}{l}\text { o programa com a Poesia Concretista dos } \\
\text { anos } 60 \text {. } \\
\text { Os alunos fazem prova com questões de } \\
\text { múltipla escolha ou dissertativas, } \\
\text { seguindo o modelo de vestibulares. }\end{array}$ & $\begin{array}{c}\text { de literatura. A leitura e a participação } \\
\text { dos alunos em sala de aula, } \\
\text { conduzidos pelos professores para } \\
\text { desvendar alguns mitos que } \\
\text { acompanham o texto literário (como } \\
\text { "literatura é tortura", "textos clássicos } \\
\text { são difíceis e chatos") é um caminho } \\
\text { para que o aluno saiba LER e } \\
\text { CONSTRUIR SENTIDO. } \\
\text { Indiscutivelmente, a imposição dos } \\
\text { clássicos assusta e os programas } \\
\text { (sobretudo os apostilados) devem ser } \\
\text { revistos para que a literatura ganhe seu } \\
\text { espaço no cotidiano dos alunos. }\end{array}$ & $\begin{array}{l}\text { mente. O resultado da imposição de } \\
\text { clássicos é a aversão completa que } \\
\text { jovens do Ensino Médio e, sobretudo os } \\
\text { que se preparam ao vestibular, têm pela } \\
\text { literatura clássica. Não leem Viagens na } \\
\text { minha terra, mas têm John Green em } \\
\text { mãos, já que não Ihes foi imposto, mas } \\
\text { veio da propaganda boca a boca que a } \\
\text { LEITURA e o CONTATO com a obra por } \\
\text { parte de seus amigos e familiares } \\
\text { tiveram. Literatura deveria ser uma } \\
\text { disciplina centrada em reuniões de } \\
\text { leitura nas escolas, cada aluno tento um } \\
\text { primeiro contato e escolhendo um livro } \\
\text { na estante para ler na escola ou em } \\
\text { casa. }\end{array}$ \\
\hline P3 & $\begin{array}{c}28 / 05 / 2014 \\
02: 00: 43\end{array}$ & 1 semestre & $\begin{array}{c}\text { Dou aula de Português em um cursinho } \\
\text { popular preparatório para vestibular e } \\
\text { para "vestibulinho". Minha turma, no caso, } \\
\text { é justamente para o vestibulinho, ou seja, } \\
\text { adolescentes que querem entrar no } \\
\text { Ensino Médio em uma escola técnica, ou } \\
\text { fazer nelas um curso técnico. A } \\
\text { coordenação do cursinho determinou este } \\
\text { semestre que os alunos devem ler } 1 \text { livro } \\
\text { por bimestre, escolhidos pela própria } \\
\text { coordenação pedagógica. Ao final do } \\
\text { bimestre, o professor escolhe se deseja } \\
\text { fazer prova ou pedir um trabalho. Não há } \\
\text { espaço no calendário de aulas para aulas } \\
\text { dedicadas exclusivamente às obras lidas } \\
\text { (o que é uma pena, em minha opinião). O } \\
\text { que faço é tentar comentar alguma coisa } \\
\text { com os alunos, sempre que sobra algum } \\
\text { tempo nas aulas regulares (ou seja, } \\
\text { quase nunca). A ideia da coordenação é } \\
\text { fazê-los ler mais para aprimorar a }\end{array}$ & $\begin{array}{c}\text { Proporcionar o contato dos alunos } \\
\text { (para muitos, o primeiro contato) com } \\
\text { obras consideradas importantes pela } \\
\text { sociedade da qual fazem parte - e, } \\
\text { assim ampliar o repertório artístico e } \\
\text { cultural dos alunos. } \\
\text { Há também uma função estética, } \\
\text { própria do contato com obras de arte - } \\
\text { e nesse sentido, uma função vinculada } \\
\text { ao próprio direito do aluno à fruição de } \\
\text { um bem cultural. } \\
\text { Outra função é refletir sobre a } \\
\text { linguagem, seus usos e recursos, } \\
\text { estilos do autor. } \\
\text { Também é possível ao aluno, pela } \\
\text { literatura, refletir sobre o mundo social } \\
\text { e mesmo pessoal, alargando horizontes } \\
\text { de experiências por meio da leitura e } \\
\text { de eventuais discussões dela } \\
\text { decorrentes. }\end{array}$ & $\begin{array}{c}\text { Já me questionaram por que tinham que } \\
\text { ler, uma vez que não gostavam de ler. } \\
\text { Também já me perguntaram por que } \\
\text { aquele livro, e não um outro de sua } \\
\text { própria escolha. } \\
\text { Acredito que, por trás das perguntas, } \\
\text { esteja um desconforto em relação à } \\
\text { obrigação da leitura, além de questões } \\
\text { de gosto pessoal. }\end{array}$ \\
\hline
\end{tabular}




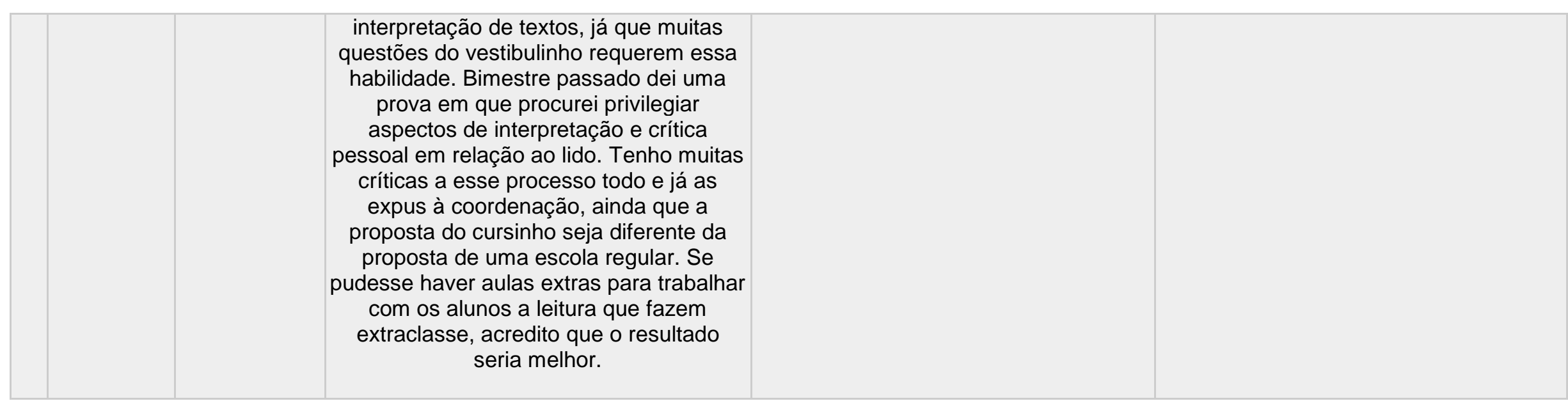




\section{Anexo 4}

Tabela 2 - Respostas dos alunos e ex-alunos ao questionário

\begin{tabular}{|c|c|c|c|c|c|c|}
\hline & $\begin{array}{l}\text { Indicação } \\
\text { de data e } \\
\text { hora }\end{array}$ & $\begin{array}{l}\text { 1) Atualmente, você } \\
\text { é estudante do } \\
\text { Ensino Médio? Se } \\
\text { sim, em qual série } \\
\text { você está } \\
\text { matriculado? Se } \\
\text { não, há quantos } \\
\text { anos terminou os } \\
\text { seus estudos no } \\
\text { Ensino Básico e } \\
\text { qual a sua atual área } \\
\text { de formação? }\end{array}$ & $\begin{array}{l}\text { 2) Você tem (ou já teve) } \\
\text { aulas de literatura? Como } \\
\text { são (ou eram) essas aulas? }\end{array}$ & $\begin{array}{l}\text { 3) Você gosta (ou } \\
\text { gostava) dessas } \\
\text { aulas? Por quê? }\end{array}$ & $\begin{array}{c}\text { 4) Você acha que } \\
\text { aprende ou já } \\
\text { aprendeu algo útil } \\
\text { para a sua formação } \\
\text { ou para a sua vida } \\
\text { nessas aulas? Se } \\
\text { sim, o que? Se não, } \\
\text { por quê? }\end{array}$ & $\begin{array}{l}\text { 5) Você percebe alguma função } \\
\text { no ensino de literatura nas } \\
\text { escolas? Se sim, qual função? Se } \\
\text { não, por quê? }\end{array}$ \\
\hline A1 & $\begin{array}{c}25 / 05 / 2014 \\
15: 53: 37\end{array}$ & $\begin{array}{c}\text { Fazem } 5 \text { anos que } \\
\text { completei o Ensino } \\
\text { Médio. } \\
\text { Sou formado } \\
\text { Tecnólogo em } \\
\text { Sistemas para } \\
\text { Internet e atualmente } \\
\text { curso um bacharelado } \\
\text { em Design Digital. }\end{array}$ & $\begin{array}{c}\text { Sim. As aulas eram (em sua } \\
\text { maioria) guiadas pelo livro } \\
\text { didático escolhido pela } \\
\text { professora, que por sua vez, } \\
\text { baseava-se nos estudos das } \\
\text { escolas literárias, que } \\
\text { utilizava-se de textos de } \\
\text { grandes autores para } \\
\text { exemplificar a questão. } \\
\text { Também eram sugeridos } \\
\text { livros para leitura, a maioria } \\
\text { clássicos da literatura luso- } \\
\text { brasileira, de autores como } \\
\text { Machado de Assis, Eça de } \\
\text { Queiroz, entre outros, que } \\
\text { eram relacionados com as } \\
\text { escolas literárias que } \\
\text { estudávamos. }\end{array}$ & $\begin{array}{l}\text { Não gostava. Achava } \\
\text { que a professora } \\
\text { explorava muito mal } \\
\text { uma matéria que } \\
\text { poderia se mostrar } \\
\text { muito além daquilo } \\
\text { que fora proposto, um } \\
\text { conteúdo } \\
\text { relativamente "raso". }\end{array}$ & $\begin{array}{c}\text { Sim, para a minha vida } \\
\text { especificamente. A } \\
\text { literatura serviu para } \\
\text { contextualizar } \\
\text { momentos históricos } \\
\text { importantes, melhorar } \\
\text { minha escrita e } \\
\text { vocabulário e } \\
\text { compreensão de } \\
\text { textos. }\end{array}$ & $\begin{array}{l}\text { Sim, ela serve para ensinar aos } \\
\text { alunos diversas perspectivas de } \\
\text { perceber o mundo, construir um } \\
\text { outro olhar de seu arredor, talvez } \\
\text { mais crítico até. Mas acredito que, } \\
\text { como acontece em outras } \\
\text { disciplinas do Ensino Médio, ela é } \\
\text { abordada de maneira rasa, não } \\
\text { fomenta a curiosidade do aluno e } \\
\text { acaba tendo um papel de } \\
\text { coadjuvante no ensino. }\end{array}$ \\
\hline
\end{tabular}


Sim, sou estudante do 25/05/2014 ensino médio, estou 17:01:11 no $3^{\circ}$ ano do ensino médio.

\section{Tenho. É interessante, dicas de bons livros, e livros que normalmente caem em vestibular}

Já tive, eram aulas sobre a

A3 $25 / 05 / 2014$ $17: 01 \cdot 35$

Sim, 3 ensino médio literatura no Brasil, Portugal, poemas, etc.

Já tive na escola e eram muito boas. A professora,

Cristiane Escolástico, da Escola Verá Cruz, fez FFLCH e era uma eximea professora e era uma apaixonada pela literatura.
Sim, pois gosto de ler tudo que envolve literatura.

Sim, pois pretendo fazer psicologia, e este curso requer muita leitura.

Sim, porque precisamos gostar de ler e conhecer as obras que caem no vestibular.

Sim, toda matéria tem algo de útil para

Não gosto, porque ensinam muitas coisas desnecessárias. parte dela mas alguma coisa sempre é importante.

Não, porque acho que não usa nada.
Terminei há 5 anos o

A4 \begin{tabular}{c|c}
$25 / 05 / 2014$ & $\begin{array}{c}\text { ensino médio e hoje } \\
\text { sou professor de } \\
\text { matemática. }\end{array}$
\end{tabular}

Gostava pois me interesso pelo assunto e porque a professora, Cristiane Escolástico da Escola Vera Cruz que fez FFLCH, dava aula com paixão

Sim, eram aulas

Conclui o Ensino

A5 25/05/2014 $21: 44: 30$ atuo em escolas e
Sim, já tive no Ensino Médio e posteriormente na formação bastante válidas.

Porque nos
Sim, leituras críticas e discernimento sobre a tradição e a sociedade
Sim. História,

pensamentos e

interesses pelas Letras.

Revista Eletrônica Literatura e Autoritarismo: Dossiê no 15 - ISSN 1679-849X

http://cascavel.ufsm.br/revistas/ojs-2.2.2/index.php/LA/index
Eu percebo sim. Claro! Literatura brasileira é quase que necessária para a vida das pessoas. As grandes obras, pelo menos, ajudam a constituir a identidade do Brasil, assim como as músicas do chico Buarque, Gil e Caetano. O Brasil não seria Brasil sem José de Alencar, Rosinha, Machado Drummond e etc. Eu percebo muito isso nos sambas enredo do passado

( e de hoje em dia também) tem muitas passagens que remetem a isso: essas Obras que já estão

firmamentadas na cultura brasileira que, na verdade, vive e se desenvolve na cabeça do povo.

Gosto pela leitura; leitura crítica; aplicação histórico-política; manutenção sadia da tradição e 


\section{Bárbara Machado Martins}

\begin{tabular}{|c|c|c|c|c|c|c|}
\hline & & $\begin{array}{l}\text { centro sociais, curso } \\
\text { licenciatura em } \\
\text { Filosofia. }\end{array}$ & $\begin{array}{l}\text { especifica que tenho. Eram } \\
\text { aulas interessantes, mesmo } \\
\text { envolventes, mas pouco } \\
\text { produtivas. Poderia } \\
\text { potencializar a leitura em } \\
\text { dinâmicas coletivas, } \\
\text { potencializar a inter- } \\
\text { disciplinariedade e os } \\
\text { debates críticos a partir das } \\
\text { leituras propostas. }\end{array}$ & $\begin{array}{l}\text { encaminhavam a } \\
\text { reflexão. }\end{array}$ & $\begin{array}{c}\text { através da leitura de } \\
\text { textos. }\end{array}$ & cultura etc.. \\
\hline A6 & $\begin{array}{c}25 / 05 / 2014 \\
22: 39: 18\end{array}$ & Sim, 3 ano & Ruins & $\begin{array}{l}\text { Não, professor não } \\
\text { passa enteresse pro } \\
\text { aluno }\end{array}$ & Não aprendi nada & $\begin{array}{c}\text { Não, pq a gente não usa fora da } \\
\text { escola }\end{array}$ \\
\hline A7 & $\begin{array}{c}25 / 05 / 2014 \\
22: 45: 46\end{array}$ & $\begin{array}{l}\text { Sim, estou no } 3 \text { o ano } \\
\text { do Ensino Médio }\end{array}$ & $\begin{array}{c}\text { Eu tenho, a professora passa } \\
\text { vários livros que vai estar no } \\
\text { vestibular }\end{array}$ & $\begin{array}{l}\text { Sim, pq é bom saber } \\
\text { e ler os livros dos } \\
\text { autores do nosso } \\
\text { país. }\end{array}$ & $\begin{array}{l}\text { Sim, as palavras dos } \\
\text { livros de literatura são } \\
\text { bem cultas, é bom } \\
\text { para o vocabulário. }\end{array}$ & $\begin{array}{l}\text { Sim, ajuda com o que os alunos } \\
\text { tenham incentivo para a leitura }\end{array}$ \\
\hline A8 & $\begin{array}{c}28 / 05 / 2014 \\
19: 19: 53\end{array}$ & $\begin{array}{l}\text { Não, sou estudante } \\
\text { do Ensino Superior. } \\
\text { Faço Relações } \\
\text { Internacionais. }\end{array}$ & $\begin{array}{l}\text { Já tive, no ensino Médio. } \\
\text { Eram muito boas, com leitura } \\
\text { de obras famosas, professora } \\
\text { recitava também poemas e } \\
\text { explorávamos as obras a } \\
\text { fundo. }\end{array}$ & $\begin{array}{l}\text { Gostava bastante. } \\
\text { Eram bem interativas } \\
\text { e palpáveis. }\end{array}$ & $\begin{array}{l}\text { Acho que aprendi sim. } \\
\text { Não algo específico, } \\
\text { mas a interpretar } \\
\text { melhor textos e } \\
\text { encontrar mensagens } \\
\text { subentendidas. }\end{array}$ & $\begin{array}{c}\text { Percebo! Exatamente no sentido do } \\
\text { que eu aprendi, exposto na } \\
\text { pergunta anterior. }\end{array}$ \\
\hline A9 & $\begin{array}{c}30 / 05 / 2014 \\
20: 17: 03\end{array}$ & $\begin{array}{c}\text { Não, terminei há } 6 \\
\text { anos o ensino médio } \\
\text { e atualmente estou no } \\
\text { ultimo ano do curso } \\
\text { de fisioterapia. }\end{array}$ & $\begin{array}{l}\text { Sim, já tive, mas não como } \\
\text { uma matéria separada mas } \\
\text { sim dentro da matéria de } \\
\text { Língua Portuguesa. As aulas } \\
\text { eram boas porque a } \\
\text { professora era boa, elas eram } \\
\text { explicativas, a professora } \\
\text { passava a parte teórica e } \\
\text { mandava a gente ler livros e }\end{array}$ & $\begin{array}{l}\text { Sim, sempre gostei. } \\
\text { Como adoro ler, as } \\
\text { aulas de literatura me } \\
\text { intrigavam e } \\
\text { instigavam muito. }\end{array}$ & $\begin{array}{c}\text { Sim, toda a história, as } \\
\text { fases/era de cada } \\
\text { época. }\end{array}$ & $\begin{array}{l}\text { Com certeza sim. A literatura, } \\
\text { principalmente a nacional, é muito } \\
\text { importante para se aprender sobre } \\
\text { os autores renomados, suas } \\
\text { contribuições para a Língua } \\
\text { Portuguesa, sem contar que leitura } \\
\text { é essencial na vida das pessoas e a } \\
\text { literatura tem esta função, fazer com }\end{array}$ \\
\hline
\end{tabular}


A FUNÇÃO DO ENSINO DE LITERATURA: PONTO DE CONVERGÊNCIA E DE RAMIFICAÇÃO DE PERSPECTIVAS

\begin{tabular}{|c|c|c|c|c|c|c|}
\hline & & & fazer resumos deles. & & & $\begin{array}{c}\text { que os alunos queiram cada vez } \\
\text { mais e mais ler. }\end{array}$ \\
\hline A10 & $\begin{array}{c}30 / 05 / 2014 \\
20: 30: 15\end{array}$ & $\begin{array}{l}\text { Terminei em 2009, há } \\
5 \text { anos e minha atual } \\
\text { área de formação é } \\
\text { Comunicação Social } \\
\text { (Publicidade, } \\
\text { Propaganda e } \\
\text { Marketing) }\end{array}$ & $\begin{array}{c}\text { Sim, era uma aula } \\
\text { complementar da disciplina } \\
\text { português no ensino médio, } \\
\text { mas era apenas um período } \\
\text { de } 50 \text { min por semana e a } \\
\text { aula era muito fraca sem } \\
\text { nenhum tipo de } \\
\text { aprofundamento. }\end{array}$ & $\begin{array}{l}\text { Gostava de ler } \\
\text { porque era algo meu, } \\
\text { as aulas não } \\
\text { pareciam de muita } \\
\text { serventia, por isso } \\
\text { não gostava. }\end{array}$ & Não. & $\begin{array}{l}\text { Com certeza, a função é habilitar o } \\
\text { gosto pela leitura no aluno. Esse } \\
\text { gosto pela leitura pode formar } \\
\text { profissionais melhor } \\
\text { capacitados/informados e cidadãos } \\
\text { com uma cultura mais ricas. }\end{array}$ \\
\hline A11 & $\begin{array}{c}01 / 06 / 2014 \\
18: 30: 31\end{array}$ & $\begin{array}{l}\text { Terminei a } 4 \text { anos e } \\
\text { não estudei mais }\end{array}$ & Ruins & $\begin{array}{l}\text { Não porque nao tive } \\
\text { um bom professor }\end{array}$ & Não aprendi nada util & $\begin{array}{l}\text { Não porque a gente não usa aquilo } \\
\text { na vida }\end{array}$ \\
\hline A12 & $\begin{array}{l}01 / 06 / 2014 \\
18: 42: 09\end{array}$ & $\begin{array}{l}\text { Não, terminei em } \\
\text { 2013. Estou cursando } \\
\text { arquitetura e } \\
\text { urbanismo. }\end{array}$ & $\begin{array}{l}\text { Já tive. Eram boas e bem } \\
\text { produtivas. }\end{array}$ & $\begin{array}{c}\text { Sim, pois } \\
\text { aprendíamos muito } \\
\text { sobre a cultura } \\
\text { literária, } \\
\text { principalmente do } \\
\text { nossa país, o que pra } \\
\text { mim é muito bom } \\
\text { saber. }\end{array}$ & $\begin{array}{l}\text { Sim, pois muitas } \\
\text { coisas que aprendi } \\
\text { nas aulas me } \\
\text { ajudaram a entrar em } \\
\text { uma boa faculdade. }\end{array}$ & $\begin{array}{l}\text { Sim, a de mostrar e ensinar mais } \\
\text { sobre culturas e história, o que no } \\
\text { meu ponto de vista são informações } \\
\text { importantes para se saber. }\end{array}$ \\
\hline A13 & $\begin{array}{l}01 / 06 / 2014 \\
21: 20: 06\end{array}$ & $\begin{array}{l}\text { Sim, } 3 \text { ano do ensino } \\
\text { Médio }\end{array}$ & $\begin{array}{l}\text { Tenho. A professora manda a } \\
\text { gente ler os livros e encaixa } \\
\text { eles nos períodos historicos }\end{array}$ & $\begin{array}{c}\text { Gosto da professora e } \\
\text { do tema }\end{array}$ & $\begin{array}{l}\text { Sim, porque eu coloco } \\
\text { em outros contextos o } \\
\text { que eu aprendo em } \\
\text { literatura e adiciona a } \\
\text { minha bagagem } \\
\text { cultural }\end{array}$ & $\begin{array}{l}\text { Literatura é uma coisa que foi e é } \\
\text { importante, um conhecimento } \\
\text { necessário das formas de } \\
\text { manifestação da historia e da } \\
\text { cultura do pais }\end{array}$ \\
\hline
\end{tabular}

Revista Eletrônica Literatura e Autoritarismo: Dossiê no 15 - ISSN 1679-849X 